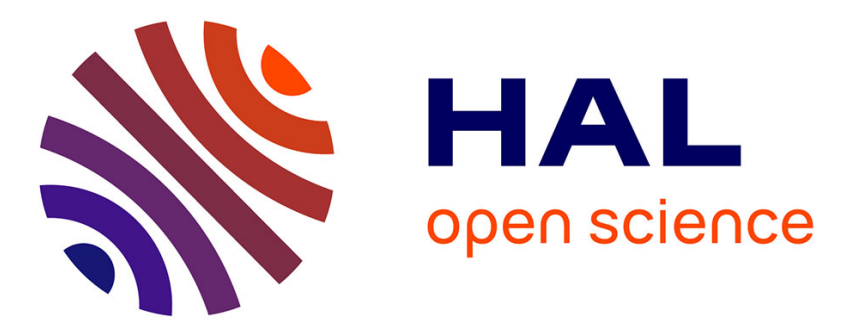

\title{
Food neophobia in the context of a varied diet induced by a weight reduction program in massively obese adolescents.
}

Natalie Rigal, M.-L. Frelut, Marie-Odile Monneuse, Claude Marcel Hladik, Bruno Simmen, Patrick Pasquet

\section{To cite this version:}

Natalie Rigal, M.-L. Frelut, Marie-Odile Monneuse, Claude Marcel Hladik, Bruno Simmen, et al.. Food neophobia in the context of a varied diet induced by a weight reduction program in massively obese adolescents.. Appetite, 2006, 46, pp.207-214. hal-00551902

\section{HAL Id: hal-00551902 https://hal.science/hal-00551902}

Submitted on 4 Jan 2011

HAL is a multi-disciplinary open access archive for the deposit and dissemination of scientific research documents, whether they are published or not. The documents may come from teaching and research institutions in France or abroad, or from public or private research centers.
L'archive ouverte pluridisciplinaire HAL, est destinée au dépôt et à la diffusion de documents scientifiques de niveau recherche, publiés ou non, émanant des établissements d'enseignement et de recherche français ou étrangers, des laboratoires publics ou privés. 
Research Report published in 2006 in :

Appetite, $46: 207-214$

\title{
Food neophobia in the context of a varied diet induced by a weight reduction program in massively obese adolescents.
}

\author{
Natalie Rigal ${ }^{\mathrm{a}}$, Marie-Laure Frelut ${ }^{\mathrm{b}}$, Marie-Odile Monneuse ${ }^{\mathrm{c}}$, \\ Claude-Marcel Hladik ${ }^{\mathrm{c}}$, Bruno Simmen ${ }^{\mathrm{c}}$, Patrick Pasquet.
}

a Université Paris 10, Département de psychologie, 200, av. de la république, 92000 Nanterre, France rigal@u-paris10.fr

${ }^{\mathrm{b}}$ Saint Vincent de Paul University Hospital, av. Denfert-Rochereau, 75014 Paris, France et Centre thérapeutique pédiatrique, 95580 Margency, France - $\underline{\text { frelut@club-internet.fr }}$

${ }^{\mathrm{c}}$ Centre National de la Recherche Scientifique and Muséum National d'Histoire Naturelle, 4, av du petit chateau, 91800 Brunoy, France - monneuse@ccr.jussieu.fr ; hladik@ccr.jussieu.fr ; simmen@ccr.jussieu.fr ; ppasquet@mnhn.fr

\section{Corresponding author}

E-mail adress:rigal@u-paris10.fr (Natalie Rigal)

Telephone : 0033140977506

Fax : 0033140977158

\begin{abstract}
Previous studies in humans have shown that short to middle-term pre-exposure to multiple foods can reduce the negative response to novel foods (neophobia). In order to explore the effects of a long-term exposure to varied foods on food neophobia, we studied a population of obese adolescents observed in a longitudinal protocol in which the multiple food experiences are induced by a residential weight reduction program (WRP) that encourages the consumption of a wide variety of foods. Seventy-two massively obese adolescents (22 boys) filled the Food Neophobia Scale (FNS, Pliner \& Hobden, 1992) and an ad hoc food familiarity and liking questionnaire at the beginning and at the end of the program (mean duration: 8.9 months). Their scores were compared to those of a control group of 51 adolescents (14 boys) tested within a similar period. FNS results show a decrease of food neophobia, without significant difference between
\end{abstract}


the control group and the WRP subjects, although only WRP have encountered new foods experiences as attested by the familiarity and liking results. Methodological considerations, concerning the characteristics of the participants, the nature of the multiple food exposure and the food neophobia measurements, will be proposed to explain differences among studies.

Key-words : food neophobia, exposure to variety, food liking, obesity, weight loss, adolescence

\section{Introduction}

Food neophobia, as indicated by several studies using the Food Neophobia Scale (FNS, Pliner \& Hobden, 1992), shows large individual variations in human populations. These variations have been partly described through classical demographic variables, mainly age and sexe (e.g., Pelchat \& Pliner, 1995; Pliner, 1994; Pliner \& Loewen, 1997), socio-economic status (Flight, Leppard, \& Cox, 2003) and culture (Ritchey, Frank, Hursti, \& Tuorila, 2003). They have also been related to variations in temperamental traits, such as sensation seeking, anxiety, emotivity, humeur and neuroticism (Loewen \& Pliner, 2000; Galloway, Lee, \& Birch, 2003; Pliner \& Loewen, 1997; Steptoe, Pollard, \& Wardle, 1995; MacNicol, Murray, \& Austin, 2003, respectively). Little systematic attention has been devoted to the impact of food experiences on food neophobia. However some studies have attempted to address the question, using different approaches.

Correlational studies, using FNS scores, indicated that neophobia was negatively related to the number of novel foods sampled (Koivisto \& Sjöden, 1996, 1997; Raudenbush, Schroth, Reilly, \& Frank, 1998), familiarity with specific novel foods (Pliner \& Hobden, 1992; Tuorila, Lähteenmäki, Pohjalainen, \& Lotti, 2001), familiarity with foreign cuisines (Pliner \& Hobden, 1992) and multiple culinary training (Frank \& Kalisewicz, 2000). Altogether, these results indicate modest but significant and repeated links between neophobia and food experiences. Although it is plausible that experiences with foods impact positively the willingness to try new foods, the direction of the causal arrow remains unclear: one could also argue that the more neophilic individuals tend to seek for more experiences with a wider variety of foods. Thus, experimental data were necessary to determine whether neophobia can be reduced by specific food experiences.

In this vein, Pliner and co-workers used a short term experimental paradigm (i.e., one day studies) to test the hypothesis that the reluctance to try new foods is underlyed by the notion that new foods are unpalatable (“bad-tasting novel food schemas”). They exposed adults (Pliner, Pelchat, \& Grabski, 1993) and children aged 7-9 or 10-12 (Loewen \& Pliner, 1999) to multiple palatable novel or familiar foods. The 
prediction that only the novel good tasting condition will decrease the level of subsequent neophobia was confirmed for adults and older children, but not for younger children: their willingness to taste novel foods was only affected by the familiar-good tasting condition. The results of these two studies indicate a positive effect of prior exposure to multiple palatable foods on food neophobia: these foods have to be novel in the case of adults and old children, and familiar in the case of younger children.

The last category of studies, carried out on newborn rats (see for example Capretta, Petersik, \& Stewart, 1975) and on human babies (Gerrish \& Menella, 2001), used middle-term experimental design to evaluate the importance of early flavour variety to enhance later acceptance of new foods. Capretta et al. showed that weanling rats exposed to a variety of different flavoured waters for 12 days were more likely to accept a novel flavour than were rats exposed to a single flavour only. More recently, results from Gerrish and Menella indicated that infants fed with different vegetables for 9 days ate significantly more of a novel food after the exposure period than before the exposure period, whereas infants fed to a single vegetable did not.

The experimental studies cited above lead finally to the conclusion that pre-exposure to multiple foods increases readiness to accept unfamiliar foods. This effect appears rather general in that it is seen in animals and humans ranging from infants to adults, and is effective in short- and middle-term protocols. However, these studies are in small number, and we do not know yet the conditions necessary to produce this decrease. It seems that the level of familiarity and palatability, as well as the number of foods proposed in the pre-exposure phase and in the test phase, play a important role in the phenomenon. Moreover, the impact of these different factors appears to depend upon age.

Our study provides data allowing to extend the experimental findings of Pliner and co-workers (1993, 1999) as well as Gerrish and Menella (2001) by filling gaps concerning the age of the participants, the duration and the nature of the multiple foods pre-exposure. A population of adolescents was observed in a longitudinal protocol in which the multiple food experiences are induced by a residential nine-months Weight Reduction Program (WRP) for massively obese patients. Insofar the program is mainly focused on the proposition of a balanced diet, participants are encouraged to consume a wide variety of foods. So, compared to previous studies, the multiple food exposure is longer and more naturalistic. To evaluate its effectiveness, we assessed the subjects' preferences with the assumption that, because of the well-known exposure effect, the preference for new foods repeatedly served during the cure will increase. Provided that this assumption is satisfied, this study will allow to test the hypothesis that food neophobia will decrease in the adolescents exposed to the WRP, as a major effect of multiple food exposure, whereas it should remain stable in a group of adolescents not submitted to the WRP. 


\section{Methods}

\section{Participants}

Seventy-two massively obese adolescents (50 girls, 22 boys) mean age 14.7 yrs (10 to 17) were examined twice: at the beginning (T1) and at the end (T2) of a Weight Reduction Program (WRP) they followed in 2001 and 2002 at the Margency Clinical Centre near Paris (France).

A sample of 51 control subjects (37 girls, 14 boys) was recruited in two secondary schools in the neighbourhoods of Margency, to form groups with comparable age $(t=0.04, p=0.96)$ and sex ratio $\left(\chi^{2}=\right.$ $0.19, p=0.66)$. Although demographic data were not collected, most adolescents within the area are known to be under the French median for income and education, which is reflected in our samples. Control subjects were also examined and tested twice, with a delay of 9 months corresponding to the mean duration of the stay of the WRP subjects (8.9 months \pm 3.8$)$.

In both WPR and control subjects the body height was measured to the nearest mm, using a portable stadiometer. The weight of each participant was measured, in light clothing, to the nearest $100 \mathrm{~g}$, using a digital scale. The control sample included $27 \%$ overweight subjects (according to the international reference by Cole, Bellizzi, Flegal, \& Dietz, 2000), representing the current prevalence in the local population.

\section{Design of the Weight Reduction Program}

The study was conducted at the Margency Clinical Centre where adolescents of both sexes stayed for six months to one year for a residential weigh loss program. Participants eat all of their meals at the clinical centre during the week. All of them go back home for weekend and short vacations. So, depending on the duration of the cure, the number of meals consumed in the centre may vary but always exceeds 450 .

The WRP combines a balanced diet, nutritional courses, and daily physical activities. A major goal is to allow adolescents to get used to a varied diet that meets national recommanded allowances (RDAs) for adolescents of the same age. The energy content assigned is based on the French daily recommended allowances for adolescents of the same age and sex with low physical activity level. Patients are served four meals per day. Breakfasts include fruit or fruit juice, cereal (i.e., cornflakes), bread or rusk with butter and marmalade, milk ( $0 \%$ or $20 \%$ fat) or dairy products (yoghurt - plain or with fruits -, white cheese 0 $\%$ or $20 \%$ fat), and a hot drink (tea, coffee, or chocolate). A free choice is allowed every day. Lunches and diners include a starter (a vegetable served with 2 tea spoons of a French dressing, or a soup), a main course (alternatively starchy foods or vegetables with varied meat, fish or eggs), a dairy food (several varieties of cheese or yoghurt or white cheese) and a fruit (raw or cooked). Mustard and salt are available. Several spices are used on regular basis in accordance to the recipes, mainly aromatic herbs, oregano, thyme, and curry. A 
snack is proposed in the afternoon that is similar to breakfast but may include a chocolate bar as well. Water is the only drink available during the day and main meals. Light sodas are served once per week during the afternoon snack. Highly energetic foods are not proposed. Light versions (calorie reduced) are encouraged for butter, milk, white cheese and other categories of cheeses, mayonnaise, sodas, chewing gums and sugar. Exotic dishes or meals are served on a regular basis in order to allow children to discover new tastes (Chinese, Caribbean, Mexican, African). The size of the portions has to remain within a limited caloric range (2000 - 2600 Kcal according to the day's appetite) with vegetables and fruits available ad libitum.

The WRP aims at encouraging participants to consume a wide variety of foods, especially among fruits and vegetables, and among reduced energy products. Variety is also encouraged for the breakfast that should account for about $20 \%$ of the daily energy intake. Although most foods served at Margency are known of subjects in the French cultural context, some of them may not be usually served at the family table where a limited repertoire represents specific habits (Fischler, 1988). As in most French collective systems for children, the foods served during the WRP cover a very broad range (e.g., Nicklaus, Boggio, Chabanet, \& Issanchou, 2005), presumably larger than the one served at home because of families specificities.

\section{Food familiarity and liking}

Each subject, in both samples, rated a 60 items Food Familiarity and Liking Questionnaire (FFLQ) at $\mathrm{T} 1$ and $\mathrm{T} 2$. The items were randomly presented. Food familiarity was first assessed by a binary response (Yes/No) to the question "have you already tasted this food?". In case of a positive answer, the subject was asked to indicate his/her liking on a nine-point scale labelled from "I don't like at all" (1) to "I like a lot" (9).

The FFLQ includes seven food categories (see Table 1) which differ in the frequency of exposure. Fruits and vegetables, calorie-reduced foods and breakfast foods represent three categories very repeatedly offered and for which variety is probably larger than in the participants' home. Foods rarely served were tested through two categories: some animal products and some relatively high energy foods. The list also included foods never served because of their very high caloric density or because of their unusual occurrence in the French adolescents' diet. We also included spices as one category because of our parallel interest in flavour responses. 
Table 1: The 60 items Food Familarity and Liking Questionnaire (FFLQ)

\begin{tabular}{|c|c|c|c|}
\hline Fruits and vegetables & Kiwi & Breakfast foods & Cereals \\
\hline$(20)$ & Lemon & (7) & Coffee \\
\hline & Pear & & Semi-skimmed milk \\
\hline & Pineapple & & Plain yoghurt \\
\hline & Aubergine & & Rusk \\
\hline & Broccoli & & White cheese $20 \%$ fat \\
\hline & Cauliflower & & Yoghurt with fruits \\
\hline & Celery in purée & Animal products & Boiled egg \\
\hline & Cooked endive & (6) & Fresh fish \\
\hline & Cooked beetroot & & Guinea-folw \\
\hline & Courgette & & Liver \\
\hline & Green beans & & Shrimps \\
\hline & Kind of French bean (flageolet) & & Turkey \\
\hline & Leeks & Relatively high density foods & Black chocolate \\
\hline & Peas & (9) & Bon-bon \\
\hline & Radish & & Camembert \\
\hline & Raw cabbage & & Coca-Cola \\
\hline & Raw endive & & Fresh cream \\
\hline & Spinach & & Mayonnaise \\
\hline & Turnips & & Raw milk \\
\hline Never served foods & Blood sausage & & Sugar \\
\hline (6) & Cress & & White cheese $40 \%$ fat \\
\hline & Salted groundnuts & Calorie-reduced foods & Creamed milk \\
\hline & Saussage (saucisson) & (8) & White cheese $0 \%$ fat \\
\hline & Sparkling water & & Light butter \\
\hline & Sweetened baby food & & Light Coca-Cola \\
\hline Spices & Aromatic plants & & Light mayonnaise \\
\hline$(4)$ & Hot spices & & Light white cheese \\
\hline & Mustard & & Mineral water \\
\hline & Salt & & Sweetener \\
\hline
\end{tabular}

Different scores are calculated for each subject from the FFLQ: (a) number of unknown foods (sum of 'No' responses to the familiarity question); (b) mean food liking (mean of all liking scores given for the foods that have already been tasted); (c) food category likings (mean liking scores for each of the seven food categories). Higher scores indicate higher likings. For all ratings, both WRP and control subjects were tested at least two hours after their last meal.

\section{Neophobia rating}

We used a French translation of the Food Neophobia Scale (FNS) validated by Ton Nu (1996) on adolescents, which slightly differs in the answering modalities from Pliner's pioneer FNS version (Pliner \& Hobden, 1992). Each subject at T1 and T2, filled this 13 items/4 points (disagree a lot, disagree, agree, agree a lot, respectively from 1 to 4) scale questionnaire. According to the phrasing of the original questionnaire, seven items were reverse-scored, so that higher scores are indicative of a greater neophobia. Individual food neophobia scores were equal to the mean of ratings for the 13 items. 
Statistical analysis

A two-between (Sex, Group of subjects: WRP vs. control), one-within (Period: T1 vs T2) mixedmodel ANOVA was performed on the FNS, mean food liking, and food category liking scores. Any effect of intervention will appear as an interaction Group of subjects $\times$ Period. Considering the non-normality of the distribution of the number of unknown foods variable (Kolmogorov-Smirnov test for normality, $D=$ $0.21, p=0.01$ ), non-parametric analyses were used for comparison between Groups (Mann-Withney test), and for comparison between Periods (Wilcoxon test) on this variable. All analyses were performed with the Statistica 6.0 software (Statsoft, Inc, Tulsa, OK, USA).

\section{Ethics}

This study was conducted in accordance with the Helsinki II declaration. It was part of the weight reduction program on obese adolescent, under medical supervision. Concerning the control subjects, oral consent was required, after the parents, being informed of our goals and methods, signed a consent form.

\section{Results}

\section{Body Mass Index}

As a result of the WRP, a significant decrease of BMI from $38.0 \mathrm{~kg} / \mathrm{m}^{2}$ to $28.9 \mathrm{~kg} / \mathrm{m}^{2}$ in the obese adolescents was observed between T1 and T2 (paired $t$-test, $t=21.82, p<0.0001$ ). Control subjects followed the standard pattern of growth, with a BMI varying from $21.4 \mathrm{~kg} / \mathrm{m}^{2}$ at T1 to $21.6 \mathrm{~kg} / \mathrm{m}^{2}$ at T2 (paired $t$-test, $t=-0.89, p=0.37)$.

\section{Number of unknown foods}

A significant decrease of the number of unknown foods in the FFLQ was observed in WRP subjects between T1 and T2 $(T=175.5, p=0.001)\left(M d n_{\mathrm{WRP}-\mathrm{T} 1}=4, M d n_{\mathrm{WRP}-\mathrm{T} 2}=1\right)$. No such a decrease was found in the control group during the same time lapse of observation $(T=396, p=0.11)\left(M d n_{\text {CONTROL-T1 }}=6\right.$, $M d n_{\text {CONTROL-T2 }}=5$ ). The number of unknown foods was lower for WRP participants than for control subjects at T1 and T2 $(U=1110, p<0.001$, and $U=764.5, p<0.001$, respectively).

\section{Neophobia and liking scores}

Cronbach's $\alpha$ was calculated at T1 for the FNS data and for the liking ratings in the various food categories. A satisfactory internal consistency was found for FNS $(\alpha=0.84)$, fruits and vegetables $(\alpha=$ 0.86), calorie reduced foods $(\alpha=0.65)$. Lower Cronbach's $\alpha$ characterised the other food categories $(0.56 \leq$ $\alpha s \geq 0.59)$. 
First, a two-between (Sex, Groups of subjects), one-within (Period) ANOVA was performed. A main sex effect was found for the mean food liking, $F(1)=18.19, p<0.001$, fruits and vegetables, $F(1)=10.03, p$ $<0.001$, breakfast items $F(1)=10.17, p<0.001$, reduced calorie foods, $F(1)=4.73, p<0.05$, energy dense foods, $F(1)=14.61, p<0.001$, and spices, $F(1)=14.84, p<0.001$. Girls rank the fruits and vegetables category, as well as the reduced calorie foods, higher than boys. Boys reported higher scores than girls for the mean food liking, breakfast items, energy dense foods, and spices. No sex effect was found for FNS, animal products category, and never served foods. These results, because they are consistent with previous French adolescents' studies (e.g., Fischler \& Chiva, 1985 - except for the animal products which are often reported to be preferred by boys than by girls -), indicated that subjects responded adequately to the FFLQ.

Second, as on the target score, i. e. food neophobia, no principal or interactive effect of sex was shown, this variable was no more included in a subsequent ANOVA (Table 2). Concerning the food neophobia scores, a main significant effect was found only for the period: FNS scores decreased in both groups of subjects between T1 and T2. Consequently, FNS scores were equivalent between groups (WRP and control) at T1 and T2. All food likings (mean and for the various categories) were significantly different between groups, with WRP subjects systematically scoring higher than control subjects. A main period effect was observed for the mean food liking, the fruits and vegetables and the breakfast categories, with higher scores obtained at T2. The most interesting result is the Group $\times$ Period interaction, which reached statistical significance for the mean food liking, and 3 food category likings (fruits and vegetables, breakfast foods, and calorie-reduced foods), with an increase of the scores between T1 and T2 only observed in WRP subjects.

Table 2: Descriptive statistics and ANOVA results for food neophobia, mean food liking and food category likings

\begin{tabular}{|c|c|c|c|c|c|c|c|c|c|c|c|c|c|c|}
\hline \multirow[b]{3}{*}{ Food variables } & \multicolumn{4}{|c|}{$\mathrm{WRP}^{\mathrm{a}}$ subjects } & \multicolumn{4}{|c|}{ Control subjects } & \multicolumn{2}{|c|}{ Group $^{\mathrm{b}}(\mathrm{G})$} & \multicolumn{2}{|c|}{ Period $^{\mathrm{b}}(\mathrm{P})$} & \multicolumn{2}{|c|}{$\mathrm{G} \times \mathrm{P}^{\mathrm{b}}$} \\
\hline & \multicolumn{2}{|c|}{$\mathrm{T} 1$} & \multicolumn{2}{|c|}{$\mathrm{T} 2$} & \multicolumn{2}{|c|}{$\mathrm{T} 1$} & \multicolumn{2}{|c|}{$\mathrm{T} 2$} & \multirow[b]{2}{*}{$\mathrm{F}$} & \multirow[b]{2}{*}{$\mathrm{p}$} & \multirow[b]{2}{*}{$\mathrm{F}$} & \multirow[b]{2}{*}{$\mathrm{p}$} & \multirow[b]{2}{*}{$\mathrm{F}$} & \multirow[b]{2}{*}{$\mathrm{p}$} \\
\hline & $\mathrm{m}$ & $\mathrm{SD}$ & $\mathrm{m}$ & $\mathrm{SD}$ & $\mathrm{m}$ & $\mathrm{SD}$ & $\mathrm{m}$ & SD & & & & & & \\
\hline \multicolumn{15}{|l|}{ FNS $^{c}$} \\
\hline Food neophobia & 2.35 & 0.54 & 2.20 & 0.53 & 2.35 & 0.51 & 2.21 & 0.49 & 0.026 & ns & 8.84 & $* * *$ & 0.29 & ns \\
\hline \multicolumn{15}{|l|}{ FFLQ $^{d}$} \\
\hline Mean food liking & 7.05 & 0.71 & 7.29 & 1.23 & 6.31 & 0.68 & 6.29 & 0.68 & 45.31 & $* * *$ & 4.23 & * & 5.16 & $*$ \\
\hline \multicolumn{15}{|l|}{ Food Category likings } \\
\hline - Fruits and vegetables & 6.30 & 1.08 & 6.69 & 1.23 & 5.70 & 1.02 & 5.76 & 0.84 & 15.95 & $* * *$ & 8.26 & $* * *$ & 4.66 & $*$ \\
\hline - Breakfast foods & 7.32 & 1.11 & 7.83 & 0.99 & 6.93 & 0.96 & 6.84 & 1.14 & 11.99 & $* * *$ & 7.57 & $* * *$ & 4.92 & $* *$ \\
\hline - Calorie-reduced foods & 7.47 & 0.93 & 8.01 & 0.90 & 6.60 & 1.20 & 6.27 & 1.14 & 54.52 & $* * *$ & 0.03 & ns & 14.7 & $* * *$ \\
\hline - Animal products & 7.38 & 1.05 & 7.41 & 1.17 & 6.51 & 1.26 & 6.87 & 1.26 & 12.03 & $* * *$ & 3.48 & ns & 1.13 & ns \\
\hline - High energy foods & 7.50 & 1.02 & 7.47 & 1.02 & 6.51 & 1.08 & 6.54 & 1.14 & 26.45 & $* * *$ & 0.03 & ns & 1.80 & ns \\
\hline - Spices & 7.20 & 1.32 & 7.29 & 1.50 & 6.09 & 1.56 & 5.82 & 1.47 & 7.62 & $* * *$ & 0.00 & ns & 1.21 & ns \\
\hline - Never served foods & 7.23 & 1.20 & 7.20 & 1.23 & 6.54 & 1.08 & 6.57 & 1.17 & 7.20 & $* * *$ & 0.00 & ns & 0.16 & $\mathrm{~ns}$ \\
\hline
\end{tabular}

Note. ${ }^{\mathrm{a}}$ Weight Reduction Program; ${ }^{\mathrm{b}} d f=1 ;{ }^{\mathrm{c}}$ Judgements from I agree a lot (1) to I disagree a lot (4) ; ${ }^{\mathrm{d}}$ Judgements from "I don't like at all" (1) to "I like a lot" (9)

$* p<0.05$, two-tailed. $* * p<0.01$, two-tailed. $* * * p<0.001$, two-tailed. 


\section{Discussion}

The effectiveness of new food experiences provided by the WRP

The efficiency of the Weight Reduction Program was attested by the BMI reduction of the target group during the study. However, the hypothesis that food neophobia will decrease as a major effect of the WRP is not confirmed by our data, since no significant difference in the decrease with time was found between the WRP and the control groups.

One could have explained this result by the fact that the WRP subjects have not encountered major changes in their food environment, but some evidences do not support this interpretation: (a) The decrease of the number of unknown foods, observed only in the WRP group, indicates that new foods have been actually tasted during the WRP; (b) the increase of liking for some foods only in the WRP group may suggest that such changes are due to novel foods experiences. Indeed, only the categories of foods for which a large variety of items is offered and/or that are very repeatedly served (because of their reputation to facilitate weight loss), such as fruits/vegetables, calorie reduced foods or breakfast foods, are more appreciated after the cure. The increasing liking for these foods may result from the exposure effect (Zajonc, 1968) ${ }^{1}$ and previous studies (see review in Rigal, 2005) have shown that repeated consumption of a food that is not very familiar leads to an increasing liking for this food; (c) previous obervations at the Margency Clinical Centre (Frelut, Potier De Courcy, Christides, Guillan, \& Emery-Fillon, 2000) shows that the folate intake of adolescents following a WPR increases significantly, attesting a higher consumption of green vegetables during the cure than before the cure.

Altogether these findings attest that the WRP succeeded to provide new and varied food experiences, especially as regards repeated consumption of fruits and vegetables and reduced energy foods.

\section{Comparison with previous studies}

Our finding of the absence of a major effect of the WRP on food neophobia does not match the results of previous studies showing a positive effect of varied and multiple food experiences on subsequent food neophobia in rats (Capretta et al., 1975), human infants (Gerrish \& Menella, 2001), children (Loewen \& Pliner, 1999) and adults (Pliner et al., 1993). This discrepancy could be surprising since the exposure to multiple food experiences was maintained for a long period in our study (mean duration $=9$ months), whereas the published experimental works never exceeded 9 days. Methodological considerations, concerning the characteristics of the participants, the nature of the multiple food exposure and the food neophobia measurements, will be proposed to explain differences among studies. 
Characteristics of the participants. The age and the BMI status of the WRP subjects could be involved since our study is the first applied to obese adolescents. Considering the "bad-tasting novel food schemas" proposed by Loewen and Pliner (1999, see introduction), we may assume that WRP subjects had not to learn that new foods can be palatable, because they displayed positive attitudes toward foods since the beginning of the cure (higher likings and familiarity than control subjects). Furthermore, one may wonder whether the developmental period investigated here, i.e. adolescence, is beyond the sensitive period during which one could learn that a novel food does not necessarily taste bad. In this respect, whereas Capretta et al. (1975) indicated that the multiple food exposure was effective for immature rats, but not for adult rats, Pliner et al. (1993) showed a positive effect with human adults. Thus, the age interpretation is not clear-cut, and one cannot rule out the possibility of an age-dependent effect.

Nature of the food exposure. Since Loewen and Pliner (1999) showed that the multiple exposure effect on subsequent neophobia occurs only with palatable foods, the lack of response to the WRP multiple exposure might be due to the low palatability of foods repeatedly served, mostly fruits and vegetables, reputed to be despised by children and adolescents (e.g., for French population, Fischler \& Chiva, 1985). However, even if liking ratings for fruits and vegetables are the lowest among the list proposed in both WRP and control group, their position above the neutral value (Table 1) shows that non-palatability of foods does not necessarily explain the absence of the multiple exposure effect.

Method to assess food neophobia. In all previous studies, measurements are reactions to foods actually present such as the amount eaten, the willingness to taste, or choices (Gerrish \& Menella, 2001; Loewen \& Pliner, 1999; Pliner et al., 1993, respectively). These food task methods differ from the evaluation on the FNS which, as a scale, implies declarative answers to general statements, without any actual food elicitation.

The methodological distinction between task and scale is found for psychological variables other than neophobia, such as anxiety. In this particular case, the distinction task vs. scale is related to the conceptual distinction between trait and state. In a review, Endler and Kocovski (1999) indicated that anxiety as a state may be evaluated with behavioural assessment techniques (e. g., time reaction to stressful stimuli) or physiological measurements (e.g., electrodermal responses), whereas scales are always used to assess anxiety as a trait. Can the conceptual (state $v s$. trait) and methodological (task $v s$. scale) distinction for anxiety be applied to food neophobia?

Conceptually speaking, neophobia as a trait and as a state have been already distinguished (e.g., Pliner, 1994). Neophobia presents characteristics known as supporting the definition of a temperamental trait: it generates (a) important individual differences (Galloway et al., 2003; Pliner \& Hobden, 1992; Potts 
\& Wardle, 1998), (b) inserted into a coherent personality cluster (Galloway et al., 2003; Pliner \& Loewen, 1997), c) that remains relatively stable with age (Nicklaus et al., 2005; Skinner, Carruth, Bounds, Ziegler, \& Reidy, 2002). Studies of the Patricia Pliner's research group also attest to the existence of neophobia as a state. Thus the level of expressed neophobia can be modulated by context modalities, such as fear and hunger (Pliner, Eng, \& Krishman, 1995), arousal (Pliner \& Loewen, 2002; Pliner \& Melo, 1997), flavour principle (Pliner \& Stallberg-White, 2000; Stallberg-White \& Pliner, 1999), nutrition and taste information (MacFarlane \& Pliner, 1997; Martins, Pelchat, \& Pliner, 1997; Pelchat \& Pliner, 1995), and modelling (Hobden \& Pliner, 1995).

Methodologically speaking, it appears that when the focus is on neophobia as a trait, scales are used (Pliner, 1994; Pliner \& Hobden, 1992; Pliner \& Loewen, 1997) whereas, when the interest is on neophobia as a state, food tasks are used, such as the willingness to taste unfamiliar foods (MacFarlane \& Pliner, 1997; Martins et al., 1997; Pelchat \& Pliner, 1995; Pliner \& Melo, 1997; Pliner \& Stallberg-White, 2000; Stallberg-White \& Pliner, 1999) or food choices (Hobden \& Pliner, 1995; Pliner et al., 1995; Pliner \& Loewen, 2002). Food tasks, with the actual presence of foods, either actually eaten or supposed to be eaten, would imply an emotional response. It is known that emotionality as a personality trait may affect responses to some psychological items (Kogovsek \& Ferligov, 2005), and this could be also true for emotionality induced by food tasks. Scales, and especially those such as FNS based on general statements, would be cognitively more demanding. In this case, the emotional response would be less acute than when foods are present.

Accordingly, in the present study where the FNS was used to assess neophobia, the results would mostly concern the trait dimension, which does not appear to be sensitive to a change in the food environment.

\section{Food neophobia evolution with age}

Our results indicate that food neophobia decreases with age both in the WRP and in the control groups. The intensity of other temperamental traits such as neuroticism (Canals, Vigil-Colet, Chico, \& Marti-Henneberg, 2005), sensation seeking (Martin et al., 2002) and openness to experiences (McCrae et al., 2002) also vary during adolescence. Many studies attest that food neophobia decreases during childhood (for a review, Rigal, 2005), but only few have focused on adolescence, all cross-sectional and based on the FNS, without consensual conclusions. Whereas Nicklaus et al. (2005) found that food neophobia remains stable between the age of 13 and 22, Ton $\mathrm{Nu}$ (1996) as well as Koivisto and Sjöden (1996) reported a significant decrease from mid-adolescence (14 to 15 years of age). 


\section{Conclusion}

It appears as a major conclusion of this study that when adolescents are exposed to a varied diet, out of their usual food environment and for a long duration, their level of food neophobia, assessed with the FNS, does not vary differently from the one of a control group, although their food preferences do vary. Several interpretations have been proposed. The most coherent with the previous empirical evidences concerns the way to assess neophobia. In order to confirm this interpretation, a new study should be undertaken using both food tasks and FNS to evaluate the impact of food experiences, with the hypothesis that variation of neophobia is observed only with the food task approach. In further studies, food neophobia, the reluctance to taste novel foods, should be clearly conceived either as a trait (a relatively stable individual's predisposition to respond negatively to novel foods), or a state (a transitory negative emotion

elicited by the idea to taste a specific novel food). The choice of the method used to evaluate food neophobia (a scale or a food task) should depend on the focus on individual differences or on state situational differences.

Nevertheless, the process underlying the positive effect of prior exposure to multiple foods on food neophobia found previously remains unclear. Whereas the idea of Pliner (i. e., bad-tasting novel food schema) is convincing, it does not necessarily apply to infants (see Gerrish \& Menella, 2001) or to animals (see Capretta et al., 1975) that may have not enough cognitive capacities to elaborate such a generalised schema.

At the clinical level this study highlight the importance of issues on the existence of personality traits related to food behaviour — such as neophobia — with the scope to improve the long-term efficiency of weight reduction programs in obese adolescents.

Acknowledgements

We wish to thank, for their help and cooperation, all the staff of the Margency Center (Croix Rouge Française) and the teachers of the secondary schools, as well as all participants who kindly responded to our tests and questionnaires. This study was supported by a grant of the CIV (Centre d'Information sur les Viandes). Special thanks to anonymous reviewers for their constructive comments.

This paper is dedicated to Professor Matty Chiva, who initiated the study but is no longer among us to learn about the results. 


\section{References}

Canals, J., Vigil-Colet, A., Chico, E., \& Marti-Henneberg, C. (2005). Personality changes during adolescence: the role of gender and pubertal development. Personality and Individual Differences, 39 , 179-188.

Capretta, P. J., Petersik, J. T., \& Stewart, D. J. (1975). Acceptance of novel flavours is increased after early experience of diverse tastes. Nature, 254, 689-691.

Cole, T. J., Bellizzi, M. C., Flegal, K. M., \& Dietz, W.H. (2000). Establishing a standard definition for child overweight and obesity worldwide: international survey. British Medical Journal , 320, 1240-1243.

Endler, N. S., \& Kocovski, N. L. (2001). State and trait anxiety revisited. Anxiety Disorders, 15, 231-245.

Fischler, C. (1988). Food, self and identity. Social Science Information, 27, 275-292.

Fischler, C., \& Chiva, M. (1985). Food likes, dislikes and some of their correlates in a sample of french children and young adults. In J. M. Diehl \& C. Leitzmann (Eds.), Measurement and determinants offood habits and food preferences (pp. 137-156). Wageningen: Department of Human Nutrition, Agricultural University.

Flight, I., Leppard, P., \& Cox, D. N. (2003). Food neophobia and associations with cultural diversity and socio-economic status amongst rural and urban Australian adolescents. Appetite, 41, 51-59.

Frank, R. A., \& Kalisewicz, S. (2000). Food experience and willingness to try novel foods. Appetite, 34, 335.

Frelut, M.L., Potier De Courcy, G., Christides, J.P., Guillan, J.-C., \& Emery-Fillon, N. (2000). Changes in folate and homocysteine status during a weight reduction program and methylene tetrahydrofolate reductase polymorphism in obese adolescents [Abstract]. International Journal of Obesity, 24 (Suppl. 1), 96.

Galloway, A. T., Lee, Y., \& Birch, L. L. (2003). Predictors and consequences of food neophobia and pickiness in young girls. Journal of the American Dietetic Association, 103, 692-698.

Gerrish, C. J., \& Mennella, J. A. (2001). Flavor variety enhances food acceptance in formula-fed infants. American Journal of Clinical Nutrition, 73, 1080-1085.

Hobden, K., \& Pliner, P. (1995). Effects of a model on food neophobia in humans. Appetite, 25, 101-114.

Kogovsek, T., \& Ferligov, A. (2005). Effects on reliability and validity of egocentered network measurements. Social Networks, 27, 205-229.

Koivisto, U.-K., \& Sjöden, P. (1996). Food and general neophobia in Swedish families: parent-child comparisons and relationships with serving specific foods. Appetite, 26, 107-118. 
Koivisto, U.-K., \& Sjöden, P. (1997). Food and general neophobia and their relationship with self-reported food choice: familial resemblance in Swedish families with children of ages 7-17 years. Appetite, 26, $107-118$.

Loewen, R., \& Pliner, P. (1999). Effects of prior exposure to palatable and unpalatable novel foods on children's willingness to taste other novel foods. Appetite, 32, 351-366.

Loewen, R., \& Pliner, P. (2000). The Food Situations Questionnaire: a measure of children's willingness to try novel foods in stimulating and non-stimulating situations. Appetite, 35, 239-250.

MacNicol, S. A., Murray, S. M., \& Austin, E. J. (2003). Relaltionships between personality, attitudes and dietary behaviour in a group of Scottish adolescents. Personality and Individual Differences, 35, 17531764.

Martin, C. A., Kelly, T. H., Rayens, M. K., Brogli, B. R., Brenzel, A., Smith, W. J., et al. (2002). Sensation seeking, puberty, and nicotine, alcohol, and marijuana use in adolescence. Journal of the Academic Childhood and Adolescence Psychiatry, 41, 1495-1502.

Martins, Y., Pelchat, M.L., \& Pliner, P. (1997). “Try it; it's good and it's good for you”: effects of taste and nutrition information on willingness to try novel foods. Appetite, 28, 89-102.

McCrae, R. R., Costa, P. T., Terracciono, A., Parker, W. D., Mills, C. J., De Fruyt, F., et al. (2002). Personality trait development from age 12 to age 18: longitudinal, cross-sectional, and cross-cultural analyses. Journal of Personality and Social Psychology, 83, 1456-1468.

McFarlane, T., \& Pliner, P. (1997). Increasing willingness to taste novel foods: effects of nutrition and taste information. Appetite, 28, 227-238.

Nicklaus, S., Boggio, V., Chabanet, C., \& Issanchou, S. (2005). Prospective study of food variety seeking in childhood, adolescence and early adult life. Appetite, 44, 289-297.

Pelchat, M., \& Pliner, P. (1995). “Try it, you'll like it.” Effects of information on willingness to try novel foods. Appetite, 24, 153-166.

Pliner, P. (1994). Development of measures of food neophobia in children. Appetite, 23, 147-163.

Pliner, P., Eng, A., \& Krishman, K. (1995). The effects of fear and hunger on food neophobia in humans. Appetite, 25, 77-87.

Pliner, P., \& Hobden, K. (1992). Development of a scale to measure the trait of food neophobia in humans. Appetite, 19,105-120.

Pliner, P., \& Loewen, E. R. (1997). Temperament and food neophobia in children and their mother. Appetite, 28, 239-254.

Pliner, P., \& Loewen, E. R. (2002). The effect of manipulated arousal on children's willingness to taste novel foods. Physiology and Behavior, 76, 551-558. 
Pliner, P., \& Melo, N. (1997). Food neophobia in humans: effects of manipulated arousal and individual differences in sensation seeking. Physiology and Behavior, 61, 331-335.

Pliner, P., Pelchat, M., \& Grabski, M. (1993). Reduction of neophobia in humans by exposure to novel foods. Appetite, 20, 111-123.

Pliner, P., \& Stallberg-White, C. (2000). "Pass the ketchup please": familiar flavors increase children's willingness to taste novel foods. Appetite, 34, 95-103.

Potts, H. W., \& Wardle , J. (1998). The list heuristic for studying personality correlates of food choice behaviour: a review and results from two samples. Appetite, 30, 79-92.

Raudenbush, B., Schroth, F., Reilly, S., \& Frank, R. A. (1998). Food neophobia, odor evaluation and exploratory sniffing behavior. Appetite, 31, 171-183.

Rigal, N. (2005). L’exposition répétée permet-elle de dépasser la néophobie alimentaire? Application chez des enfants français soumis à des produits salés [Reduction of food neophobia as a result of repeated exposure ? A study with French children exposed to salty foods]. European Review of Applied Psychology, 55, 43-50.

Ritchey, P. N., Frank, R. A., Hursti, U.-K., \& Tuorila, H. (2003).Validation and cross-national of the food neophobia scale (FNS) using confirmatory factor analyses. Appetite, 40, 163-173.

Skinner, J. D., Carruth, B. R., Bounds, W., Ziegler, P. J., \& Reidy, K. (2002). Do food-related experiences in the first 2 years of life predict dietary variety in school-aged children? Journal of Nutrition Education Behavior, 34, 310-315.

Stallberg-White, C., \& Pliner, P. (1999). The effect of flavor principles on willingness to taste novel foods. Appetite, 33, 209-221.

Steptoe, A., Pollard, T.S., \& Wardle, J. (1995). Development of a measure of the motives underlying the selection of food: the food choice questionnaire. Appetite, 25, 267-284.

Ton Nu, C. (1996). Préférences et néophobie alimentaire à l'adolescence [Food preferences and food neophobia during adolescence]. Unpublished master's thesis, ENGREF, Massy, France.

Tuorila, H., Lähteenmäki, L., Pohjalainen, L., \& Lotti, 1. (2001). Food neophobia among the Finns and related responses to familiar and unfamiliar foods. Food Quality and Preference, 12, 29-37.

Zajonc, R. B. (1968). Attitudinal effects of mere exposure [Monograph]. Journal of Personality and Social Psychology, 9 (2, Pt. 2). 